\title{
Effect of External Cues for Pedal Pacing on Breathing Pattern during Cycle Exercise
}

\author{
Nariko Takano \\ Physiology Laboratory, Department of School Health, \\ Faculty of Education, Kanazawa University, Kanazawa \\ 920
}

Takano, N. Effect of External Cues for Pedal Pacing on Breathing Pattern during Cycle Exercise. Tohoku J. Exp. Med., 1988, 156, Suppl., 103-112Fourteen subjects performed cycle exercise at work loads of 0 and $1 \mathrm{kp}$, each for 3 min, during which the pedal rate was kept constant by various external cues. Six cues were used in order : no cue (N1), a speedometer dial (S), a flashing light (F), a verbal command (V), a metronome sound (M) and no cue, again (N2). An attempt was to study the effect of these cues on breathing pattern in a lower tidel volume $\left(\mathrm{V}_{\mathrm{T}}\right)$ range during exercise, actually $\mathrm{V}_{\mathrm{T}}$ increasing to 2 times the resting levels. In $\mathrm{N} 1$ and $\mathrm{N} 2$, exercise was performed at preferred pedal rates, which were $40 \pm 4$ (mean \pm S.E.) rpm and $52 \pm 2 \mathrm{rpm}$, respectively. Pedaling to other four cues was kept at $50 \mathrm{rpm}$. Ventilatory responses during exercise were similar in all conditions of cue except N1. Increases in respiratory frequency (f) during exercise were similar in $\mathrm{S}$ but greater in $\mathrm{F}$ at $0-\mathrm{kp}$ load and in $\mathrm{V}$ and $\mathrm{M}$ at $1-\mathrm{kp}$ load, compared with N2. The greater increases in $f$ in $F, V$ and $M$ were due to greater shortening in inspiratory $\left(\mathrm{T}_{\mathrm{I}}\right)$ and expiratory $\left(\mathrm{T}_{\mathrm{E}}\right)$ durations. In any conditions of cue, $T_{1}$ and $T_{E}$ decreased with increasing $V_{T}$ in response to exercise. The present study indicates that (1) breathing pattern during rhythmic exercise is affected by external rhythmic stimuli like $F, V$ and $M$, and (2) there is no such a $V_{T}$ range that $T_{I}$ and $T_{E}$ remain constant in the $V_{T}-T_{I}$ and $V_{T}-T_{E}$ relations during exercise. cycle exercise; rhythmic cue during exercise; breathing pattern

In 1972, Clark and Euler reported that in adult humans the relation of tidal volume $\left(V_{T}\right)$ to inspiratory duration $\left(T_{I}\right)$ during rebreathing is divisible into two volume ranges : range 1 seen at a lower $V_{T}$ range in which $T_{1}$ remains constant and range 2 seen at a higher $V_{T}$ range in which $T_{1}$ decreases hyperbolically with increasing $\mathrm{V}_{\mathrm{T}}$. The range 1 was interpreted to represent a $\mathrm{T}_{\mathrm{I}}$ regulation by the bulbopontile 'clock' mechanism and the range 2, a $\mathrm{T}_{1}$ regulation by the HeringBreuer inflation reflex. Since the study of Clark and Euler (1972), the relation of lung volume to respiratory durations has been studied extensively to clarify the control mechanism of breathing pattern under a variety of conditions (Younes and Remmers 1981).

Control of breathing pattern during exercise, particularly in rhythmic exercise, has also been an intriguing subject (Kay et al. 1975; Askanazi et al. 1979; 
Bechbache et al. 1979; Lind and Hesser 1984 ; Cha et al. 1987). Among investigators, however, disagreement exists concerning the $\mathrm{V}_{\mathrm{T}}-\mathrm{T}_{\mathrm{I}}$ relation at lower $\mathrm{V}_{\mathrm{T}}$ levels during exercise. Some investigators observed range 1, as during rebreathing, i.e., a constant $\mathrm{T}_{\mathrm{I}}$ with varying $\mathrm{V}_{\mathrm{T}}$, (Maillard and Gautier 1981 ; Lind and Hesser 1984; Cha et al. 1987) while others observed a progressive decrease in $\mathrm{T}_{\mathrm{I}}$ with increasing $\mathrm{V}_{\mathrm{T}}$ (Kay et al. 1975; Askanazi et al. 1979; Bechbache et al. 1979).

In rhythmic exercise on a cycle ergometer or treadmill, breathing frequency (f) tends to be influenced by frequency of limb movement. On occasion, breathing rhythm coordinates to movement rhythm (entrainment) (Bechbache and Duffin 1977 ; Kohl et al. 1981 ; Yonge and Petersen 1983). It has been reported that the incidence of entrainment during bicycle exercise is dependent on the method to keep the pedal rate constant: a metronome signal increases the incidence than a speedometer dial (Bechbache and Duffin 1977 ; Yonge and Petersen 1983).

In the previous study with an incremental bicycle work (Takano 1988), we observed a steep increase in $f$ and hence marked decreases in $T_{1}$ and expiratory $\left(\mathrm{T}_{\mathrm{E}}\right)$ durations in the transition from rest to unloaded pedaling which was accompanied with a small increase in $V_{T}$. As $V_{T}$ increased further with increasing work load, changes in the respiratory durations slowed down. Our result was at variance with that of Lind and Hesser (1984), in spite of a similar work condition. They observed no changes in $f$ and hence respiratory durations until the work rate was increased to $40 \mathrm{~W}$, indicating a presence of range 1 in the $V_{T}-T_{I}$ and $\mathrm{V}_{\mathrm{T}}-\mathrm{T}_{\mathrm{E}}$ relations. They used a speedometer while we used a metronome to keep the pedal rate constant. Therefore, the present study was attempted to examine the effect of methods of pedal pacing on breathing pattern during cycle exercise, particularly at lower work rates.

\section{Methods}

\section{Subjects}

Fourteen healthy students, 3 males and 11 females, ranging in age from 19 to 23 , volunteered for testing. All were untrained to sport activities. They were informed as to testing procedures, but none was aware of the purpose of the experiment. The subjects gave informed consent. The test on each subject was performed at least $2 \mathrm{hr}$ after the last meal.

\section{Experimental procedures}

Each subject had a training period for $5 \mathrm{~min}$ before the test, in order to be accustomed to pedaling on a mechanically braked cycle ergometer (Monark, Sweden) at 0 and $1 \mathrm{kp}$ (kilopond) of work loads while wearing a respiratory mask. The subject was asked to pedal voluntarily slowly and fast. Following the training period, a 15 min rest on a chair was allowed, which was followed by six experimental runs with different external cues for pedal pacing (see below). Each run consisted of three periods in order: a 2 to 3 min rest on the bicycle ergometer, 3-min unloaded pedaling (work load : $0 \mathrm{kp}$ ) and 3-min loaded pedaling (work load: $1 \mathrm{kp}$ ). The subject was asked to start pedaling by a command 'start' and to maintain the pedal rate as constant as possible during pedaling. Maintenance of pedal rate 
was accomplished by giving the following six external cues: (1) with no cue (N1), (2) a speedometer dial (S), (3) a flashing light (F), (4) a verbal command "1, 2, 1, 2" (V), (5) a metronome sound (M), and (6) with no cue, again (N2). In N1 and N2, the subjects were asked to pedal at preferred rates and in $S$, to keep the dial reading at $50 \mathrm{rpm}$. In $F, V$ and $M$, the signals were given regularly at a frequency with 100 times/min, so that pedal rate was maintained at $50 \mathrm{rpm}$.

Six experimental runs with different external cues were carried out in the above mentioned order in sequence. A 15 min rest on a chair was allowed between each run. Following the last run, the subjects were questioned whether they had attempted to entrain breathing to pedaling rhythm.

\section{Measurements and data analysis}

In each run, the subject breathed through a respiratory mask (dead space: $200 \mathrm{ml}$ ) which was connected to a hot wire flowmeter for continuous measurement of respiratory flow. Respiratory gases were sampled continuously at the nose and introduced to a gas analyzer (MG-360, Medical gas analyzer, Minato Med. Sci. Co., Osaka.) for measurement of $\mathrm{O}_{2}$ (by a zirconium reaction) and $\mathrm{CO}_{2}$ (by infrared absorption). Signals from the flowmeter and gas analyzer were fed to a minicomputer (RM-200, Respiromonitor, Minato Med. Sci. Co., Osaka), which was capable of computing, on a breath-by-breath basis, tidal volume $\left(V_{T}\right)$, respiratory frequency $(f)$, minute ventilation $\left(\dot{V}_{E}\right)$, inspiratory and expiratory durations $\left(\mathrm{T}_{\mathrm{I}}\right.$ and $\mathrm{T}_{\mathrm{E}}$, respectively), $\mathrm{O}_{2}$ uptake $\left(\dot{\mathrm{VO}}_{2}\right), \mathrm{CO}_{2}$ excretion $\left(\dot{\mathrm{V}} \mathrm{CO}_{2}\right)$ and end-tidal $\mathrm{PO}_{2}$ and $\mathrm{PCO}_{2}$. An electrocardiogram was recorded using a bipolar lead and the number of $\mathrm{R}$ wave of the ECG was counted during each breath cycle so as to derive heart rate (HR in $\min$ ) in breath-by-breath.

In each run, the average values for each variable were calculated using the breath-bybreath data obtained during the last $1 \mathrm{~min}$ of each period. Date during coughs or sighs were excluded from the analysis. The tendency to coordination between pedal rate $(p)$ and respiratory frequency (f) was identified making use of the following criteria: (1) The ratio of $\mathrm{p} / \mathrm{f}$ lay on an integer or half-integer multiple within \pm 0.05 (Paterson et al. 1987) and (2) Breath-by-breath variation of $f$ during data gathering period $(1 \mathrm{~min})$ was below $10 \%$ in coefficient of variance (S.D./mean) (Yonge and Petersen 1983).

Results for all subjects were obtained as mean \pm S.E.. The responses during the runs with different external cues were compared by a paired Student's $t$-test, in which significance level was $p<0.05$.

\section{RESULTS}

In the question for entrainment, only one subject answered that she had frequently had consciously entrained breathing during exercise. Fig. la shows the time course of $f$ of this subject during the run with $V$. The $f$ had locked at 25 breaths $/ \mathrm{min}$ ( $\mathrm{p} / \mathrm{f}$ ratio: 2.00 ) during both $0-\mathrm{kp}$ and $1-\mathrm{kp}$ pedaling periods. The locking of $f$ in this subject was seen in all runs except those with $\mathrm{N} 1$ and $\mathrm{S}$. For the remaining thirteen subjects who had had no intention of conscious entrainment of $f$ to pedal rate, the occurrence of integer $p / f$ ratio was examined. Fig. $1 b$ and $c$ show examples of integer $\mathrm{p} / \mathrm{f}$ ratio; in $\mathrm{b}$, the occurrence during both $0-\mathrm{kp}$ and $1-\mathrm{kp}$ pedaling and in $\mathrm{c}$, only during $0-\mathrm{kp}$ pedaling. Table 1 summarizes the incidence of integer $p / f$ ratio during pedaling to various external cues. The incidence was similar in all cues except N1. In the run with N1, irregular breathing was seen more frequently in most subjects, presumably due to less familiarity with the test because of the first test. The incidence of integer $p / f$ 


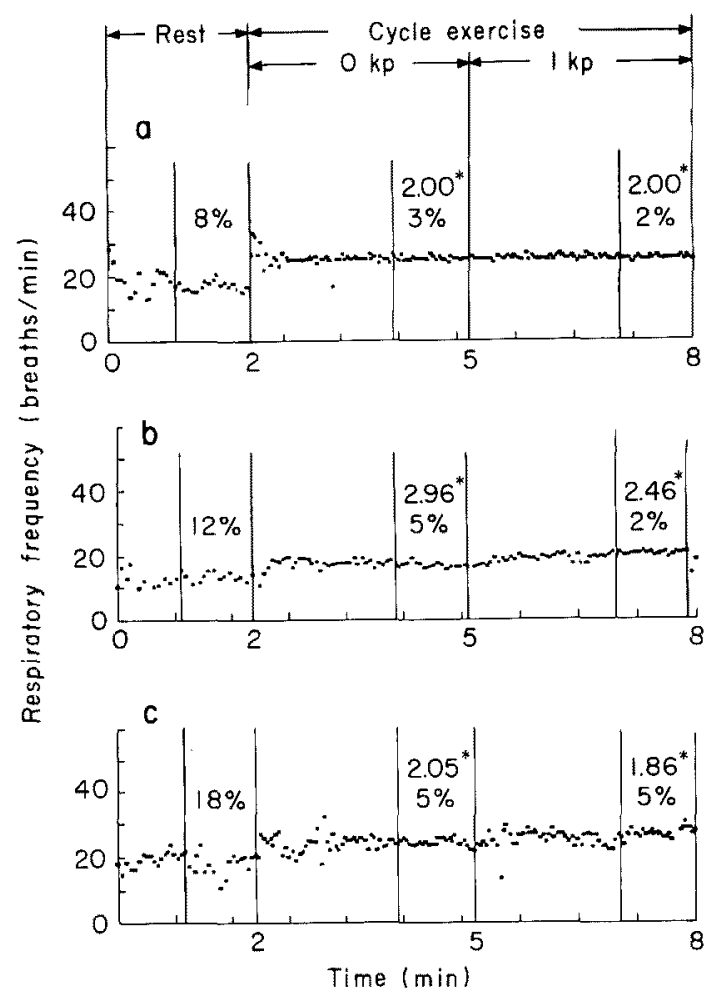

Fig. 1. The time course of respiratory frequency (f) during experimental runs. Percent value signifies breath-by-breath variation (CV) of $f$, and "ratio of pedal rate to $f(p / f)$ during the last $1 \mathrm{~min}$ of each experimental period of rest, $0-\mathrm{kp}$ and $1-\mathrm{kp}$ cycle exercise, which is shown as the section between two vertical lines. a: During almost all period of exercise, $f$ was consciously locked at a half of pedal rate. b: During exercise at work loads of 0 and 1 $\mathrm{kp}, \mathrm{f}$ changed progressively and reached the steady state, at which $\mathrm{p} / \mathrm{f}$ ratios showed integer and half-integer multiples within \pm 0.05 , respectively. $\mathrm{c}$ : Interger $\mathrm{p} / \mathrm{f}$ ratio was seen only in 0 - $\mathrm{kp}$ exercise.

TABLE 1. Number of subjects tending to interger $p / f$ ratio during pedaling to varions external cues in 13 subjects

\begin{tabular}{lcc}
\hline \multirow{2}{*}{ External cue } & \multicolumn{2}{c}{ Work load } \\
\cline { 2 - 3 } & $0 \mathrm{kp}$ & $1 \mathrm{kp}$ \\
\hline No cue (N1) & 0 & 0 \\
Speedometer (S) & 2 & 3 \\
Flashing light (F) & 3 & 4 \\
Verbal command (V) & 3 & 1 \\
Metronome (M) & 1 & 4 \\
No cue (N2) & 2 & 4 \\
\hline
\end{tabular}


ratio tended to be higher during 1-kp pedaling than during 0-kp pedaling. For each subject, integer $\mathrm{p} / \mathrm{f}$ ratio was seen on one to four of total 12 occasions of exercise ( 2 work loads with 6 external cues). Whether with or without integer $p /$ $f$ ratio, $f$ progressively changed during the course of cycle exercise, indicating no abrupt step changes (Fig. $1 \mathrm{~b}$ and $\mathrm{c}$ ) An abrupt step change in $\mathrm{f}$ during pedaling has been considered as an index of conscious coordination of $f$ to pedal rate (Yonge and Petersen 1983; Parker et al. 1985; Paterson et al. 1986). Based on the results of interger $p / f$ ratio and the time course of $f$ during exercise, we considered that in those 13 subjects, the coordination of pedaling- and breathing-rhythm, if occurred, was unintended and performed practically at unaware. Later analysis was performed on these 13 subjects.

For all variables studied, the resting values measured prior to cycle exercise were similar in all runs. Preferred pedal rate during exercise with N1 was $40 \pm$ $4 \mathrm{rpm}$ (range 26-68) at 0-kp load and $39 \pm 3 \mathrm{rpm}$ (range 28-68) at 1-kp load, whereas that in $\mathrm{N} 2$ was $52 \pm 2 \mathrm{rpm}$ (range 44-66) at both work loads. As the result of this, $\dot{\mathrm{V}}_{\mathrm{E}}$ (Fig. 2), $\dot{\mathrm{V}} \mathrm{O}_{2}$ (Fig. 2), $\dot{\mathrm{V}} \mathrm{CO}_{2}$, and HR during 1-kp pedaling were $10-15 \%$ lower in N1 than in N2, while these values during 0 -kp pedaling were similar in both $\mathrm{N} 1$ and $\mathrm{N} 2$.

Responses during pedaling to four external cues (S, F, V and $M$ ) were compared with those with no cue (N2). The values of $\dot{\mathrm{V}}_{\mathrm{E}}$ (Fig. 2), $\dot{\mathrm{V}}_{2}$ (Fig. 2),
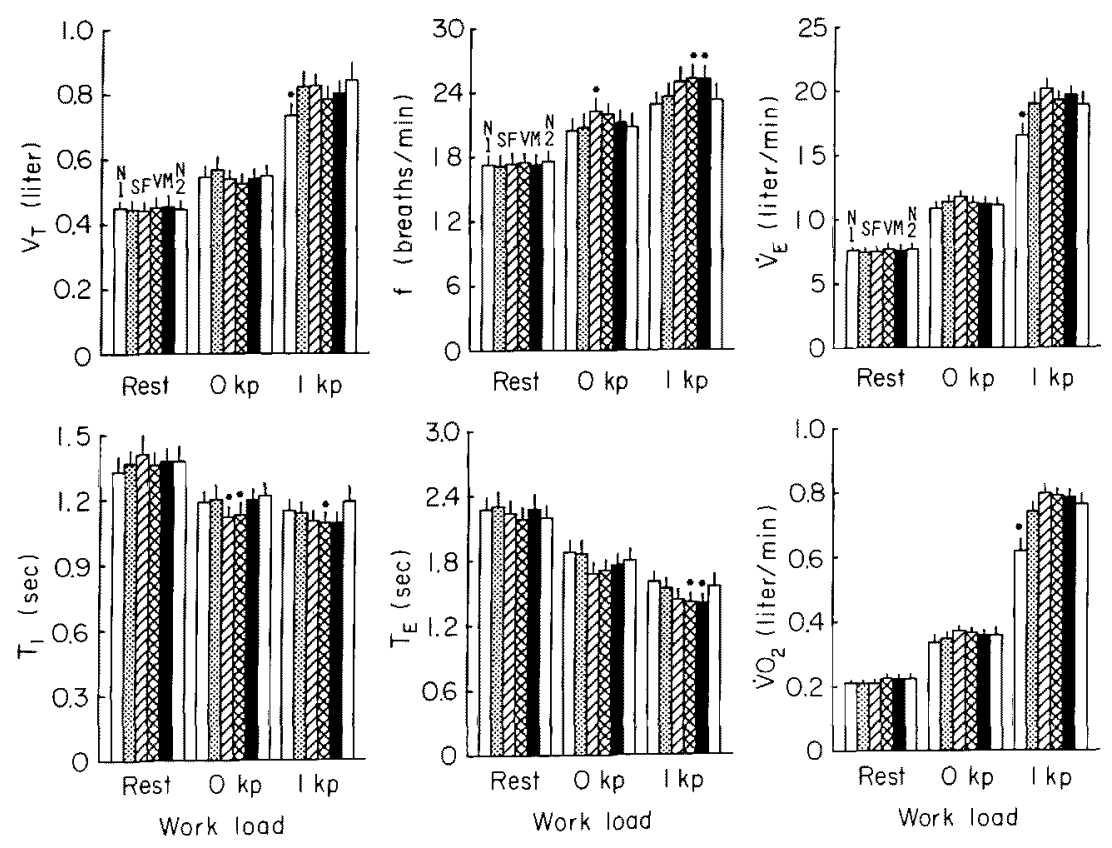

Fig. 2. Mean \pm S.E. of $\mathrm{V}_{\mathrm{T}}, \mathrm{f}, \dot{\mathrm{V}}_{\mathrm{E}}, \mathrm{T}_{1}, \mathrm{~T}_{\mathrm{E}}$, and $\dot{\mathrm{V}}_{2}$ during experimental runs with different external cues. N1, No cue, first run; S, Speedometer; F, Flashing light; V, Verbal command; M, Metronome; N2, No cue, second run. *Significant difference between N2 at $p<0.05$. 
$\dot{\mathrm{V}} \mathrm{CO}_{2}$, end-tidal $\mathrm{PO}_{2}$ and $\mathrm{PCO}_{2}$, and $\mathrm{HR}$ during exercise at 0 and $1 \mathrm{kp}$ were similar in all conditions of cues. Fig. 2 shows the data for $V_{T}, f, T_{I}, T_{E}, \dot{V}_{E}$, and $\dot{\mathrm{V}} \mathrm{O}_{2}$. In $\mathrm{N} 2$ and $\mathrm{S}$, the values of $\mathrm{V}_{\mathrm{T}}, \mathrm{f}, \mathrm{T}_{1}$ and $\mathrm{T}_{\mathrm{E}}$ during exercise were similar. The $f$ during exercise was greater in $\mathrm{F}$ at 0 -kp load and greater in $\mathrm{V}$ and $\mathrm{M}$ at 1-kp load, as compared with that in $\mathrm{N} 2$. Increases in $\mathrm{V}_{\mathrm{T}}$ during exercise tended to be less in $\mathrm{F}, \mathrm{V}$ and $\mathrm{M}$ than in $\mathrm{S}$ and $\mathrm{N} 2$, although the differences did not reach a significant level. Ventilatory responses during exercise at 0 and $1 \mathrm{kp}$ resulted in similarity in all conditions of cues. The greater increases in $f$ during exercise with $F, V$ and $M$ were mainly due to greater decreases in $T_{1}$ at $0 \mathrm{kp}$ and to greater decreases in $T_{E}$ at $1 \mathrm{kp}$, compared with those during exercise with $\mathrm{N} 2$.

The relationship between $\dot{\mathrm{V}}_{\mathrm{E}}$ and $\mathrm{V}_{\mathrm{T}}$ was studied and described as $\dot{\mathrm{V}}_{\mathrm{E}}=\mathrm{m}$ $\left(\mathrm{V}_{\mathrm{T}}-\mathrm{k}\right)$ according to Hey et al. (1966). Fig. 3 shows the average relationship in each run with different external cues. The $\mathrm{m}$ values in the runs with $\mathrm{V}$ and $\mathrm{M}$ were significantly greater than with $\mathrm{N} 2(34.1 \pm 2.1$ and $34.8 \pm 2.0$ vs. $29.1 \pm 2.5$ (unit: breaths/min), respectively).

Fig. 4 shows average relations of $\mathrm{V}_{\mathrm{T}}-\mathrm{T}_{1}$ and $\mathrm{V}_{\mathrm{T}}-\mathrm{T}_{\mathrm{E}}$. In any conditions of external cue, $T_{E}$ decreased significantly with increasing $V_{T}$ during exercise. For $\mathrm{T}_{1}$, the significant decrease with increasing $\mathrm{V}_{\mathrm{T}}$ was seen in the transition from rest to $0-\mathrm{kp}$ pedaling, independent of the condition of cue, and it was seen only in the condition of $\mathrm{M}$ in the transition from 0-kp to 1-kp pedaling. Since the decreases in $T_{I}$ and $T_{E}$ during exercise with $F, V$ and $M$ were greater than those with $\mathrm{N} 2$ and

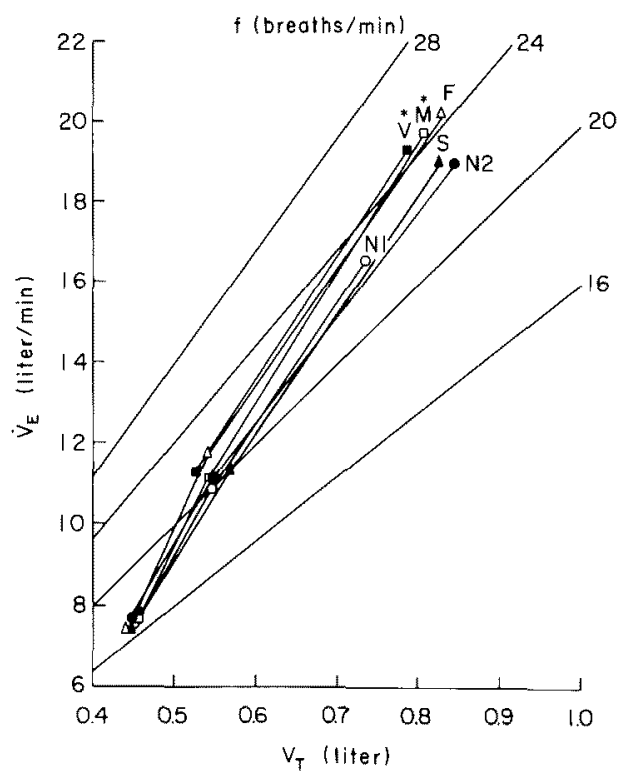

Fig. 3. $\quad \dot{\mathrm{V}}_{\mathrm{E}}-\mathrm{V}_{\mathrm{T}}$ relationship (Hey plot) during experimental runs with different external cues. For abbreviation of external cues, see Fig. 2. *Mean slope among three points for each run ( $m$ value, see text) differed significantly between run with $\mathrm{N} 2$ at $p<0.05$. 


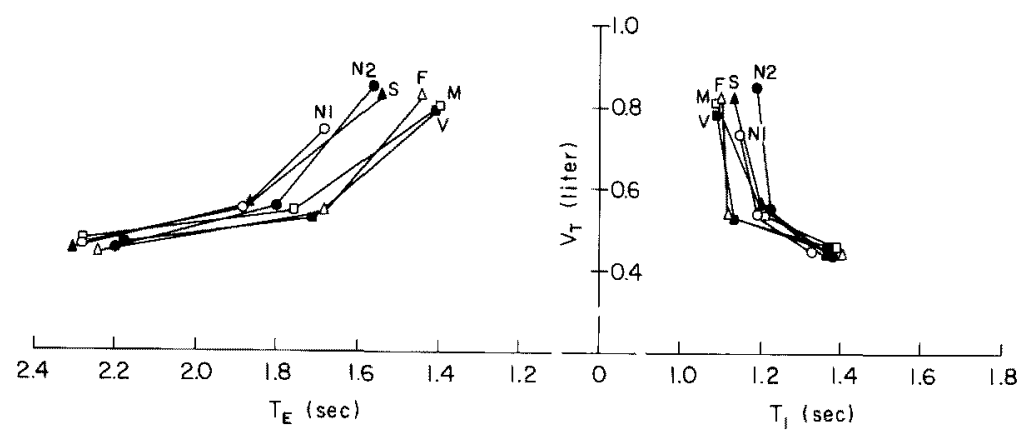

Fig. 4. The relations of $V_{T}-T_{1}$ and $V_{T}-T_{E}$ during experimental runs with different external cues. For abbreviation of external cues, see Fig. 2.

$\mathrm{S}$ (Fig. 2), the volume-time relations were shifted downward in the former three conditions.

\section{Discussion}

In the present study, the work loads were set at rather low rates ( 0 and $1 \mathrm{kp}$ ), which resulted in increases of $V_{T}$ to 2-fold, $\dot{V}_{E}$ to 3 -fold and metabolic rate to 4-fold the resting levels (Fig. 2). In such a low volume range, the breathing pattern during exercise and the effect of external stimuli on it were studied. The study demonstrated that when cycle exercise was performed keeping pace with a rhythm of an external cue such as a flashing light, a verbal command and a metronome sound, the $f$ during exercise increased to a greater extent, which was dependent on the combination of external cue and work load, than while pedaling without cue or with a speedometer (Fig. 2). The increase in $V_{T}$ during exercise tended to be less, but not significantly, with a rhythmic cue than without cue or with a speedometer, so that the ventilatory response was virtually similar in all conditions (Fig. 2). These changes in $f$ and $V_{T}$ led to increases in the $m$ value of Hey plot $\left(\mathrm{V}_{\mathrm{T}}-\dot{\mathrm{V}}_{\mathrm{E}}\right.$ relation) during exercise with a verbal command and a metronome as an external cue (Fig. 3 ).

The greater response of $f$ during pedaling to external rhythmic cues might have been brought about by such a behavioral control as to entrain $f$ to pedal rate. Previous studies on entrainment have shown that a conscious, voluntary setting of breathing rhythm to pedaling rhythm is characterized by a sudden change and locking of $f$ at a certain $p / f$ ratio (Yonge and Petersen 1983; Parker et al. 1985 ; Paterson et al. 1986). Except one subject, whose results were excluded in the data analysis, the remaining thirteen subjects had displayed no such sudden change in $f$ during the whole course of pedaling. Therefore, we considered that the occurrence of integer $\mathrm{p} / \mathrm{f}$ ratio in our subjects would have been due to unconscious coordinations of breathing rhythm to pedaling rhythm. As shown in Table 1, the incidence of integer $\mathrm{p} / \mathrm{f}$ ratio was independent of the conditions of pedal pacing. Accordingly, the greater increases in $f$ during exercise with exter- 
nal rhythmic cues are most likely to be spontaneous responses in $f$ but not to be outcomes of conscious entrainment of $f$, by learning and training, to pedal rate. Similar responses of $f$ seen in the two exercise conditions with no cue and with a speedometer would indicate that whether attention or nonattention to a cue (speedometer dial) are not causally related to response in $f$ during exercise. Thus, external rhythmic stimuli per se, irrespective of visual or auditory and irrespective of attention or nonattention to them, appear to influence the control of respiratory frequency during rhythmic exercise. Our pervious study showed that at any given levels of $\dot{\mathrm{VCO}}_{2}$ the $\mathrm{f}$ during cycle exercise was greater at $60 \mathrm{rpm}$ than at 30 rpm of pedal rate, in which pedal rate was maintained using a metronome (Takano 1988). A more frequent auditory stimulus given by a metronome during 60-rpm pedaling might have been responsible for the greater response of $f$ under that exercise condition. The present study has focused on the matter of the mode of external cue during rhythmic exercise, but not on the matter of the frequency of external cues, a further study of this point being awaited.

The effect of lung volume on $\mathrm{T}_{\mathrm{I}}$ and $\mathrm{T}_{\mathrm{E}}$ can be defined as volume threshold curves on the $\mathrm{V}_{\mathrm{T}}-\mathrm{T}_{\mathrm{I}}$ and $\mathrm{V}_{\mathrm{T}}-\mathrm{T}_{\mathrm{E}}$ relations (Clark and Euler 1972; Younes and Remmers 1981). It has been found that in adult humans, the volume threshold remains almost unchanged while $V_{T}$ is within the range of 1.5 to 2 times of the resting level (range 1). Some investigators found the range 1 to be held during exercise (Maillard and Gautier 1981 ; Lind and Hesser 1984 ; Cha et al. 1987). On the other hand, Askanazi et al. (1979) have found progressive decreases in $\mathrm{T}_{\mathrm{I}}$ and $\mathrm{T}_{\mathrm{E}}$ with increasing $\mathrm{V}_{\mathrm{T}}$ during exercise. Kay et al. (1975) and our own (Takano 1988) have observed that slow decreases in $\mathrm{T}_{\mathrm{I}}$ and $\mathrm{T}_{\mathrm{E}}$ are preceded by the steep decreases in the transition from rest to exercise. As pointed out by Bechbache et al. (1979), a volume threshold curve during exercise is affected by a number of factors: the level of chemoreflex drive, the breath-by-breath variation of breathing pattern due to oscillation of the respiratory centers, the level of consciousness or anxiety, the body temperature and the exercise rhythm. The present study demonstrated that the methods for pedal pacing during cycle exercise are also a factor affecting the $V_{T}-T_{1}$ and $V_{T}-T_{E}$ relations (Fig. 4). Interestingly, whether with or without external cues, $\mathrm{T}_{1}$ consistently decreased with increasing $\mathrm{V}_{\mathrm{T}}$ in the transition from rest to $0-\mathrm{kp}$ pedaling. This indicates the absence of range 1 in response to exercise. Bechbache et al. (1979) reported that $\mathrm{T}_{\mathrm{I}}$ change in a lower $\mathrm{V}_{\mathrm{T}}$ range was dependent on the level of anxiety to the test: $T_{1}$ unchanged with $V_{T}$ in subjects feeling uneasy about the test while it decreased progressively with $V_{\Upsilon}$ in those feeling at ease. From this study of Bechbache et al. (1979), it seems that breathing pattern at rest plays an important role in determining the $\mathrm{V}_{\mathrm{T}}-\mathrm{T}_{\mathrm{I}}$ and $\mathrm{V}_{\mathrm{T}}-\mathrm{T}_{\mathrm{E}}$ relations at a lower $\mathrm{V}_{\mathrm{T}}$ level during exercise.

In the present study, the effect of order of presentation of the experimental conditions has not been tested. An ordering effect of external stimuli has been 
found on the occurrence of entrainment during cycle exercise (Jasinskas et al. 1980) but not on breathing pattern at rest (Shea et al. 1987). Based on the results in Table 1 except for $\mathrm{N} 1$, it seems that the order of the presentation of external stimuli affected little the occurrence of entrainment in our subjects. However, whether this is the case in the $\mathrm{V}_{\mathrm{T}}-\mathrm{T}_{\mathrm{I}}$ and $\mathrm{V}_{\mathrm{T}}-\mathrm{T}_{\mathrm{E}}$ relations during exercise remains uncertain.

While it remains to be resolved what mechanism underlies by which external rhythmic cues exert the influence on breathing pattern during rhythmic exercise, behavioral and environmental conditions must be considered in interpretation of results for breathing pattern at rest (Shea et al. 1987) and during exercise (Haas et al. 1986).

\section{References}

1) Askanazi, J., Milic-Emili, J., Broell, J.R., Hyman, A.I. \& Kinney, J.M. (1979) Influence of exercise and $\mathrm{CO}_{2}$ on breathing pattern of normal man. J. Appl. Physiol., 47, 192-196.

2) Bechbache, R.R. \& Duffin, J. (1977) The entrainment of breathing frequency by exercise rhythm. J. Physiol. (Lond.), 272, 553-561.

3) Bechbache, R.R., Chow, H.H.K., Duffin, J. \& Orsini, E.C. (1979) The effects of hypercapnia, hypoxia, exercise and anxiety on the pettern of breathing in man. $J$. Physiol. (Lond.), 293, 285-300.

4) Cha, E.J., Sedlock, D. \& Yamashiro, S.M. (1987) Changes in lung volume and breathing pattern during exercise and $\mathrm{CO}_{2}$ inhalation in humans. J. Appl. Physiol., 62, 1544-1550.

5) Clark, F.J. \& Euler, C. von. (1972) On the regulation of depth and rate of breathing. J. Physiol. (Lond.), 222, 267-295.

6) Haas, F., Distenfeld, S. \& Axen, K. (1986) Effects of perceived musical rhythm on respiratory pattern. J. Appl. Physiol., 61, 1185-1191.

7) Hey, E.N., Lloyd, B.B., Cunningham, D.J.C., Jukes, M.G.M. \& Bolton, D.P.G (1966) Effects of various respiratory stimuli on the depth and frequency of breathing in man. Respir. Physiol., 1, 193-205.

8) Jasinskas, C.L., Wilson, B.A. \& Hoare, J. (1980) Entrainment of breathing rate to movement frequency during work at two intensities. Respir. Physiol., 42, 199-209.

9) Kay, J.D.S., Petersen, E.S. \& Vejby-Christensen, H. (1975) Mean and breath-bybreath pattern of breathing in man during steady-state exercise. J. Physiol. (Lond.), 251, 657-669.

10) Kohl, J., Koller, E.A. \& Jager, M. (1981) Relation between pedalling and breathing rhythm. Eur. J. Appl. Physiol., 47, 223-237.

11) Lind, F. \& Hesser, C.M. (1984) Breathing pattern and lung volumes during exercise. Acta Physiol. Scand., 120, 123-129.

12) Maillard, D. \& Gautier, H, (1981) Gas exchange during bicycle exercises preceded or not by loadless pedalling in female and male subjects. Respir. Physiol., 45, 201-216.

13) Parker, B.E., Jr., Adams, J.M. \& Hill, A.R. (1985) A computer-based data adquisition system for breathing and exercise entrainment studies. Comput. Biol. Med., 15, $279-285$.

14) Paterson, D.J., Wood, G.A., Morton, A.R. \& Henstridge, J.D. (1986) The entrainment of ventilation frequency to exercise rbythm. Eur. J. Appl. Physiol., 55, 530537.

15) Paterson, D.J., Wood, G.A., Marshall, R.N., Morton, A.R. \& Harrison, A.B.C. (1987) 
Entrainment of respiratory frequency to exercise rhythm during hypoxia. $J . A p p l$. Physiol., 62, 1767-1771.

16) Shea, S.A., Walter, J., Pelley, C., Murphy, K. \& Guz, A. (1987) The effect of visual and auditory stimuli upon resting ventilation in man. Respir. Physiol., 68, 345-357.

17) Takano, N. (1988) Effects of pedal rate on respiratory responses to incremental bicycle work. J. Physiol. (Lond.), 396, 389-397.

18) Yonge, R.P. \& Petersen, S. (1983) Entrainment of breathing in rhythmic exerise. In: Modelling and Control of Breathing, edited by B.J. Whipp \& D.M. Wiberg, Elsevier Sci. Pub. Co., New York, pp. 197-204.

19) Younes, M.K. \& Remmers, J.E. (1981) Control of tidal volume and respiratory frequency. In : Regulation of Breathing. Part 1, edited by T.F. Hornbein, Marcel Dekker, New York, pp. 621-671. 